\title{
Correction to: Different approaches to long-term treatment of aHUS due to $M C P$ mutations: a multicenter analysis
}

\author{
Verena Klämbt ${ }^{1} \cdot$ Charlotte Gimpel $^{2} \cdot$ Martin Bald $^{3} \cdot$ Christopher Gerken $^{4} \cdot$ Heiko Billing $^{5} \cdot$ Sebastian Loos $^{6}$. \\ Matthias Hansen $^{7} \cdot$ Jens König $^{8} \cdot$ Tobias Vinke $^{9} \cdot$ Carmen Montoya $^{10} \cdot$ Bärbel Lange-Sperandio $^{11}$. \\ Martin Kirschstein $^{12} \cdot$ Imke Hennies $^{13} \cdot$ Martin Pohl $^{1} \cdot$ Karsten Häffner $^{1,2}$
}

Published online: 22 September 2021

(c) IPNA 2021

\section{Correction to: Pediatr Nephrol (2021) 36:463 - 471 https://doi.org/10.1007/s00467-020-04714-0}

The authors regret that the name of the author Bärbel LangeSperandio was incorrectly rendered as "Bärbel Lange Sperandio". The original article has been corrected.

Publisher's note Springer Nature remains neutral with regard to jurisdictional claims in published maps and institutional affiliations.

The online version of the original article can be found at https:// doi.org/10.1007/s00467-020-04714-0

Karsten Häffner

karsten.haeffner@uniklinik-freiburg.de

1 Department of General Pediatrics, Adolescent Medicine and Neonatology, Medical Center, University of Freiburg, Faculty of Medicine, Mathildenstr. 1, 79106 Freiburg, Germany

2 Department of Internal Medicine IV, Medical Center, University of Freiburg, Faculty of Medicine, Freiburg, Germany

3 Olga Children's Hospital, Department of Pediatric Nephrology, Klinikum Stuttgart, Stuttgart, Germany

4 University Children's Hospital Marburg, Philipps-University, Marburg, Germany

5 Paediatrics I, University Children's Hospital, Tübingen, Germany

6 University Children's Hospital, University Medical Center Hamburg-Eppendorf, Hamburg, Germany
$7 \quad$ KfH-Nierenzentrum für Kinder und Jugendliche beim Clementine-Kinderhospital, Frankfurt, Germany

8 Department of General Pediatrics, University Children's Hospital, Münster, Germany

9 Department of Pediatrics I, University Children's Hospital of Heidelberg, Heidelberg, Germany

10 KfH Center of Pediatric Nephrology, Children's Hospital Munich Schwabing, Munich, Germany

11 Dr. v. Hauner Children's Hospital, Ludwig Maximilians University, Munich, Germany

12 Department of Pediatrics, General Hospital, Celle, Germany

13 Department of Paediatric Kidney, Liver and Metabolic Diseases, Paediatric Research Center, Hannover Medical School Children's Hospital, Hannover, Germany 